\title{
Tobacco smoking in Egypt: a scoping literature review of its epidemiology and control measures
}

Samar Fouda ${ }^{1,2}$, Mohamed Kelany ${ }^{1,2}$, Nada Moustafa ${ }^{1,2}$, Abdelrahman Ibrahim Abushouk ${ }^{3,4}$, Amro Hassane ${ }^{1,2}$, Ahmad Sleem ${ }^{1,2}$, Osama Mokhtar ${ }^{1,2}$, Ahmed Negida ${ }^{1,2,5}$ and Medhat Bassiony ${ }^{1,6}$

${ }^{1}$ Student Research Unit, Zagazig University, Egypt. ${ }^{2}$ Undergraduate students, Faculty of Medicine, Zagazig University, Egypt. ${ }^{3}$ Faculty of Medicine, Ain Shams University, Cairo, Egypt. ${ }^{4}$ NovaMed Medical Research Association, Cairo, Egypt. ${ }^{5}$ Medical Research Group of Egypt, Cairo, Egypt. ${ }^{6}$ Psychiatry Department, Faculty of Medicine, Zagazig University, Zagazig, Egypt (Correspondence to: Samar Fouda: samarsfouda@gmail.com).

\begin{abstract}
Background: According to World Health Organization (WHO) reports, the prevalence of smoking is increasing in many developing countries, including Egypt. The aim of this study is to summarize the published data in the literature about tobacco smoking in Egypt.

Methods: A computerized literature search of PubMed and relevant Egyptian journals was conducted using the relevant keywords. The findings of retrieved studies were extracted and discussed in a narrative approach.

Results: Our search retrieved 44 relevant studies. The most updated prevalence of tobacco smoking in Egypt is $22 \%$ in 2010 and is increasing. Highly significant odds ratios were reported for sibling, parent, and peer smoking as risk factors for smoking. Cardiovascular disorders, malignant tumors, and erectile dysfunction are common complications of smoking in the Egyptian population. Efforts to control tobacco smoking are available, but inadequate.

Conclusions: Tobacco smoking is a prevalent health problem in Egypt, associated with cardiovascular disorders and malignant tumors. Health education programmes should be delivered through mass media and school-based programmes to reach a large section of the Egyptian population.

Keywords: Smoking; tobacco; prevalence; control; Egypt

Citation: Fouda S; Kelany M; Moustafa N; Abushouk AI; Amro Hassane A; Ahmad Sleem; et al. Tobacco smoking in Egypt: a scoping literature review of its epidemiology and control measures. East Mediterr Health J. 2018;24(2):198-215. https://doi.org/10.26719/2018.24.2.198.

Received: 23/05/16; accepted: 06/03/17

Copyright @ World Health Organization (WHO) 2018. Some rights reserved. This work is available under the CC BY-NC-SA 3.0 IGO license (https:// creativecommons.org/licenses/by-nc-sa/3.o/igo).
\end{abstract}

\section{Introduction}

Tobacco smoking is a major avoidable cause of morbidity and is estimated to cause 450 million deaths in the next 50 years (1). According to WHO reports, smoking is currently responsible for six million premature deaths every year, of which 600000 individuals die from the effects of second-hand smoke (2). Considering the combination of poor resources and the health and financial burdens of smoking, it is essential for developing countries to battle smoking and its risk factors.

Smoking is an established risk factor for esophageal, bladder, renal and pancreatic cancers (3). In females, smoking has been recognized as an independent risk factor for cervical cancer, and is reported to accelerate menopause through its anti-estrogen effect (4). Both the American heart association (AHA) and the American Stroke Association (ASA) strongly recommended smokers to consider smoking cessation to avoid ischemic stroke and subarachnoid hemorrhage $(5,6)$. Moreover, smoking is a risk factor for communicable diseases such as tuberculosis and lower respiratory tract infections (7).

Egypt is a developing country that exhibits an increase in the extent of smoking in its population (8). From Egyptian smokers, 95\% are smoking daily. In 2004, almost 170000 tobacco-related deaths took place in Egypt
(9). Aside of years of potential life lost, approximately 3.4 billion Egyptian pounds a year are spent in dealing with tobacco-related health problems (10).

Approximately $21 \%$ of the Egyptian population is within the age range of 15 to 24 years; however, the increasing prevalence of tobacco use among Egyptians threatens this demographic (11). Although the annual population growth in Egypt is $2 \%$, the number of smokers in Egypt is estimated to increase by $8 \%$ each year $(10,12)$. The principal law for smoking prevention in Egypt was released in 1981 (Law No. 52) and several tobacco legislations were released later to supplement it including Law No. 85 (2002), Law No. 154 (2007), and Law No. 443 (2008) (13).

Many studies have been conducted to evaluate tobacco smoking prevalence, risk factors, complications, and prevention efforts in different countries. However, studies addressing smoking in Egypt are scarce. Moreover, no former study have gathered the available data about smoking prevalence, risk factors, complication and control measures in Egypt. These data have been described separately in the literature. Therefore, we performed a scoping literature review of published reports with the goal of summarizing the situation and forming a genuine idea about smoking in Egypt. 


\section{Methods}

Using Arksey's and O'Malley's scoping review methodology as a guide (9); we searched MEDLINE through PubMed, Current Psychiatry Journal, and Egyptian Psychiatry Journal through May 2015 for relevant studies. Different combinations from the following keywords: (Smoking OR tobacco OR nicotine use) AND (Prevalence OR risk factors OR cessation OR quit* OR control OR prevention OR treatment OR complications OR consequences) AND Egypt* were used.

We limited our literature search to published research articles that reported original data or secondary analysis results of surveys, conducted by national or international organizations. Studies were classified into five groups: 1) studies reporting smoking prevalence, 2) studies assessing the risk factors of smoking, 3) studies assessing smoking related complications, 4) treatment of tobacco (nicotine) dependence, and 5) prevention of tobacco smoking in Egypt. Two authors independently selected relevant studies. Eligibility screening was performed in a couple of steps: the first one was to screen abstracts for eligibility and in the next step, full-text articles of eligible abstracts were retrieved and screened.

Data of eligible studies were extracted independently by six authors using a standardized data extraction form. The extracted data included the following: 1) characters of study design, 2) characters of study population, 3) study outcomes: smoking prevalence, risk factors, complications, treatment, and prevention. Data were exported from the online form to an excel sheet, and another author resolved disagreements.

\section{Results}

Our search retrieved 218 unique citations. After screening titles and abstracts of these records, 92 full text articles were retrieved and screened. Of them, 44 full text articles were included in this study (Table 1). The retrieved studies included 33 cross-sectional studies (surveys), 9 casecontrol studies, 1 clinical trial, and 1 secondary analysis of the GATS report. Of the 44 studies, 33 were conducted in Egypt only and 11 were conducted in multiple countries including Egypt.

\section{Prevalence}

The prevalence of smoking in Egypt in 2010 was 22\% (approximately 11504500 individuals) and is increasing (2). Although the annual population growth in Egypt is $2 \%$, the number of smokers in Egypt is estimated to increase by $8 \%$ each year $(10,12)$. The results of individual studies showed a prevalence rate of tobacco smoking in Egypt that ranged from $19.7 \%$ in the Global Adult Tobacco Survey (GATS) (15) report to 30\% in Egyptian populationbased studies (16). These variations in the prevalence rates of smoking could be due to recruiting different populations, different age range of respondents, different survey years and settings, and using different diagnostic criteria or rating scales. Lower educational status, being between ages 25-64 and being employed predicted a higher risk of tobacco use (17).

As indicated in Table 1c, smoking prevalence is much less among females than males. Men (38.1\%, 95\% CI [36.8-39.4]) are much more likely to use tobacco (0.6\%, 95\% CI [0.4 to 0.9]) than women. Almost 96\% of men, who use tobacco, do so daily. Men are more likely to use manufactured cigarettes $(31.8 \%, 95 \%$ CI [30.6 to 33.1]) than shisha $(6.2 \%, 95 \%$ CI [5.6 to 6.9]) or smokeless tobacco $(4.1 \%, 95 \% \mathrm{CI}[3.4$ to 4.8$])$. Few women use tobacco (cigarettes (0.2\%), shisha (0.3\%) and smokeless tobacco (0.3\%); however, all women who currently smoke shisha do so daily.

It is important to note that: 1) the numbers of smokers in Egypt has doubled over the past 15 years (2); 2) smoking prevalence increases with age $(18) ; 3$ ) tobacco use is more common among males that are the less educated and of a lower socioeconomic class $(2,19) ; 4)$ the most updated epidemiology on shisha smoking in Egypt (2013) indicates that approximately $3.3 \%$ of the Egyptian population $(6.2 \%$ of males and $0.3 \%$ of females) use shisha (20); and 5) tobacco smoking is more prevalent among males than females; however, the numbers of females smoking has increased rapidly in the last few years due to increased exposure to western culture and increased numbers of working women $(2,21,22)$.

The current gaps in the literature concerning tobacco smoking in Egypt are:

1. Insufficient data available on smoking among youth in rural communities where majority of the Egyptian population resides.

2. Heterogenous data about the age of smoking initiation among adolescents and youth (ranging from 15 to 22.5 years in the included reports). Determining the age of initiation is important because late initiators are more capable of quitting and this knowledge can determine the appropriate timing of awareness interventions.

3. All data in the included cross-sectional studies were self-reported; therefore, the cultural traditions in Egypt and fear of shame could have underestimated the smoking prevalence, especially among females and adolescents. In this regard, the Population Council conducted a survey in 2009 that concluded $26 \%$ of Egyptian youth reported smoking; however, these figures are suggested to underestimate the actual prevalence since another study reported $42.2 \%$ of male and $5 \%$ of female youth admitted that their peers smoke.

\section{Risk factors}

Recognizing the risk factors for initiation of tobacco use among the Egyptian population is essential to guide planning of prevention programmes and define the appropriate timing of intervention with awareness campaigns. Several studies have investigated this point and concluded that neuroticism, depression, advertising, parental smoking, friends' smoking, and paid work were 
the main risk factors for tobacco use in Egypt (Table 2).

Although several studies have focused on the risk actors for smoking in the Egyptian community, few studies have targeted to identify the protective factors against smoking initation. Loffredo et al. Classified these factors into: 1) intrinsic factors such as health reasons and self-esteem, and 2) extrinsic factors such as religious beliefs, family influences, and prevention messages of control programmes. The influence of these factors needs to be further investigated and exploited to enhance prevention programs (27).

\section{Complications of smolking}

Cardiovascular system complications such as atherosclerosis and hypertension, chronic obsructive pulmonary disease (COPD), cancer bladder, pancreatic cancer, erectile dysfunction, spermatic malformation, and fetal exposure to nicotine were the commonly reported complications of smoking in Egypt.

In the study by Abdallah et al. (34), which included a population of 4733 subjects, $42.3 \%$ of the study population were smokers. Of them, $41 \%$ were atherosclerotic $60.9 \%$ asymptomatic and $39.1 \%$ symptomatic. In a study by Youssef et al. (24) that included a population of 316 subjects, $43.6 \%$ were smokers. Smoking was significantly associated with the risk of developing hypertension.

Tageldin et al. (35) conducted a cross-sectional study which included 9804 subjects from Egypt and showed a clear correlation between cumulative exposure to cigarette smoke and the frequency of COPD-related symptoms, suggesting that smoking remains a major risk factor for COPD.

A case-control study by Lafuente et al. (36) showed that smokers with metabolic deficiency, namely Glutathione S-transferase Mul, have a 4.8 fold increase in the risk of developing squamous cell carcinoma (SCC) of the bladder. Makhyoun et al. (37) performed a case-control study that found the frequency of heavy smoking was $32.2 \%$ for bladder cancer patients, compared with $14.9 \%$ in the control group. However, this difference was not noteworthy except at the age group of 40 to 49 years. Another case control study by Zheng et al. (38) showed that smoking cigarettes had a significant association with the increased risk of urinary bladder cancer with an adjusted odds ratio of 1.8 ( $95 \%$ CI [1.4 to 2.2]). Smokers had a significantly elevated risk of both urinary transitional and squamous cell carcinoma, with an OR of 2.9 (95\% CI [2.1 to 3.9]) and 1.8 (95\% CI [1.2 to 2.6]), respectively.

A case-control study by An-chi lo et al. (39) showed that smoking increased the risk of pancreatic cancer with an OR of 4.5 (95\%CI [1.9-10.7]) for smokers who ever smoked cigarettes only, and an OR of 7.8 (95\%CI [3.0 to 20.6]) for smokers who ever used multiple types of tobacco smoking.

In a case-control study by Elbendary et al. (40), the investigators recruited patients with persistent symptoms of erectile dysfunction (ED) for at least 6 months or more. Smokers were found to be at an increased risk for developing ED than nonsmokers in univariate as well as multivariate analyses $(P=0.05)$. This result was confirmed in the following year by the findings of Zedan et al. (41) that smoking significantly elevated the ED risk with an OR of 3.1.

Taha et al. (42) demonstrated that smokers with varicocele $(\mathrm{Vx})$ had an incidence of oligospermia that was ten times larger than that of nonsmokers with Vx, and five times larger than that in males who smoked but devoid of Vx. They demonstrated that smoking has a negative effect on sperm DNA fragmentation, hypoosmotic swelling test (HOS) test, seminal Zinc level, and sperm progressive motility.

In a cross-sectional study among smoking pregnant mothers, there was a considerable positive association between cotinine meconial levels and both maternal salivary and urinary cotinine levels (43). Meconium is a perfect biomarker for testing direct fetal exposure to tobacco use during the neonatal phase. Tobacco exposure was also proven to cause premature birth and intrauterine growth retardation (IUGR) (44).

\section{Treatment of tobacco use (smoking cessation)}

\section{Pharmacological and psychological interventions}

Adding a pharmacological treatment is one of the relatively recent methods to help tobacco users stop. Bolliger et al. performed a randomized placebocontrolled trial to evaluate the efficacy and tolerability of varenicline in smokers from 11 countries, including Egypt. The continuous abstinence rate (CAR) from the 9 th to the 12th week was notably higher with varenicline administration, compared to placebo (53.59\% vs. $18.69 \%$ : $P<0.0001)$, and this effect was maintained till the 24 th week $(P<0.0001)$. Therefore, Varenicline is apparently efficacious and generally well-tolerated as a smoking cessation aid for smokers in Egypt.

Bassiouny et al. (45) reported that the abstinence rate among smokers after using nicotine patches for nine weeks was $50.6 \%, 28 \%$ after six months and $25.8 \%$ at the end of the year. A third study (46) found that $47 \%$ of Egyptian smokers in their sample were able to quit smoking for three months after six sessions of counseling. Based on these studies, both pharmacological and psychological interventions were helpful for smokers, not only to quit, but also to maintain their abstinence for a long time.

\section{Factors affecting smoking cessation}

The literature suggests that multiple psychological, personal, genetic, and social factors might influence smoking cessation. Studying these factors will help selecting patients in smoking cessation programmes. In addition, individuals at higher risk of relapse are expected to receive additional social, psychological, or medical interventions to reduce their likelihood of relapse.

In a study by El-Hayawan et al. (46), previous attempts 
at smoking cessation were reported by $76 \%$ of the study participants. They found that $79.4 \%$ of subjects decided to stop smoking due to health concerns. In a crosssectional survey in Alexandria governorate, Youssef et al. (47) formulated a predictive model for quitting smoking based on marital status, age of starting smoking, duration of tobacco use, presence of chronic health problems, and awareness of the benefits of smoking cessation. This model could correctly classify $89.3 \%$ of ex-smokers.

Bishry et al. tested the association between the personality type as measured by Character Inventory-125 (TCI-125), temperament and motivation to quit smoking (48). There was no statistically considerable difference between the non-motivated and the motivated groups in terms of smoking pattern or the Fagerstorm severity index. Moreover, There was no difference of a statistical significance between both the "Motivated, Nonrelapsed" and the "Motivated, Relapsed" groups in the Fagerstorm severity index and the pattern of smoking. Correlation between the two groups (the motivated and the non-motivated) showed that there was a statistically considerable difference between the motivated group and the non-motivated group in novelty seeking $(P=0.04)$, persistence (PS) $(P=0.04)$, and cooperativeness (C) $(P=0.05)$. The novel findings in this study, concerning the association between personality profile and smoking, could be useful to develop innovative treatments for tobacco dependence and design therapeutic programs for different individuals.

\section{Smoking cessation and health care workers}

Physicians should offer counseling, nicotine substitution therapy, and oral smoking cessation medications as alternative options to tobacco smoking. In El-Kasr ElAiny Hospital, a survey study by Radwan et al. (49) examined the knowledge of health care professionals and employees about tobacco control policies in Egypt. Findings of this study were that the majority $(>90 \%)$ of the hospital employees knew the mere exposure to second-hand smoke is hazardous to health. Nurses and physicians had a more favourable attitude towards a smoking ban, when compared to administrative staff members. Hospital staff identified several barriers to the successful implementation of smoking prevention measures such as lack of enforcement of tobacco control laws, lack of penalties for those who violate them, the shortage of smoking cessation programmes, and the prevalence of smoking among physicians.

In another study in the Family Medicine Practice Centers (FMC), affiliated to Suez Canal University Hospitals, Abdelsatar et al. (50) examined family physicians' knowledge, attitudes, and practice of smoking cessation counseling. Practice scores of family physicians were assessed based on their sources of knowledge, receiving any formal training, and their perception of competency in smoking cessation counseling. Multiple choice questions were used for assessing their knowledge about the 5As approach (Ask about tobacco use every time, Advise tobacco users to quit, Assess willingness to make a quit attempt, Assist in moving the individual toward a successful quit attempt, and Arrange for followup contact) and pharmacologic methods of smoking cessation aid. Attitudes were assessed using a six item questionnaire on the importance of the topic, physician's readiness to perform counseling, and four other items adapted from a questionnaire (developed by the WHO Global Health Professionals Survey). They found that $94.7 \%$ of physicians were nonsmokers and $38.7 \%$ met one to five smoker patients daily. The majority of family physicians had favourable attitude scores (93.3\%) about smoking cessation counseling, coupled with poor practice and knowledge scores (44\% and $45.3 \%$ respectively).

The most frequent patient-related barrier, according to family physicians in their sample, was their own desire $(62.7 \%)$, while that related to the physician was their lack of training (32\%). More than half of family physicians (53\%) suggested training to enhance smoking cessation counseling skills. Most of the physicians (88\%) in this study sample responded that they were not prepared to perform smoking cessation counseling. Lack of training and time were among the barriers that call for further organization support and training intervention to improve the quality of the counseling service. This warrants the integration of effective tobacco-smoking control policies and quitting support into the study curricula of nursing and medical schools, in addition to providing cessation counseling training for both nurses and physicians.

\section{Predictors of relapse of tobacco smoking}

Bassiouny and colleagues studied patients receiving nicotine patches (45). They found that smokers who were more dependent, depressed, and less motivated for smoking cessation showed the highest rate of relapse. Therefore, they suggested that depressed or non-motivated smokers should receive additional psychological and social support while attempting to quit smoking. Another study evaluated the state-trait anxiety variable as a predictor of maintained smoking cessation (51). Results of this study showed that the anxiety trait, but not anxiety state, was a significant predictor $(P=0.01)$ of maintained smoking cessation. These results imply that anxiety trait variable can be employed to maintain smoking cessation by perceiving nicotine addiction as a continuous stressing stimulus.

A third study evaluated the correlation between personality profile and motivation to quit smoking (48). Novelty seeking, persistence, and cooperativeness were correlated with higher motivation to quit smoking, while none of personality characters were associated with smoking relapse. Based on these studies, it is recommended to do psychiatric and psychological assessment before smoking cessation and to treat the comorbid psychiatric disorders such as anxiety and depression. In addition, motivational interviewing should be added to any smoking cessation programme, not only to maximize the success rate, but also to prevent relapse. 


\section{Tobacco smoking control efforts in Egypt}

Several control measures and awareness programmes are being implemented to reduce the extent of tobacco use within the Egyptian population as follows.

\section{Health education programmes}

Youssef et al. (47) recommended that health education programmes should stress the adverse health consequences of tobacco by warning about the dangers before shifting to illustrate the benefits of cessation at any age. A later age of starting smoking has a major effect on potential cessation because those who are late initiators are less dependent on nicotine and more expected to give up smoking after a short duration (52). Therefore, it is important to put more effort into adolescents' education about smoking. In a survey of secondary school students (53), it was concluded that for each risk factor and smoking behaviour, having an extensive tobacco health education had a beneficial effect. Knowledge was the strongest forecaster of whether or not the students were current smokers. Efforts to standardize educational outreach between females and males, in addition to increasing the level of exposure to information on the health risks of smoking, may help lessen the smoking prevalence among Egyptian adolescents.

\section{Warning labels on cigarette packaging and worksite smoking bans}

Shang et al. (54) analyzed the data, released by GATS, and found that for many low- and middle-income countries, the higher rates of exposure to worksite smoking bans, the higher the odds of tobacco cessation (OR $=1.13,95 \%$ CI [1.04 to 1.22]). Exposure to warning labels was found to be associated with a greater likelihood of recent cessation in Egypt $(\mathrm{OR}=3.20,95 \% \mathrm{CI}[1.53$ to 6.68]. Exposure to anti-smoking media messaging (OR $=1.08,95 \% \mathrm{CI}[1.00$ to 1.17]), worksite smoking bans ( $\mathrm{OR}=1.11,95 \% \mathrm{CI}$ [0.99 to 1.26$]$ ), warning labels ( $\mathrm{OR}=1.03,95 \% \mathrm{CI}$ [1.01 to 1.05$]$ ), and cigarette prices ( $\mathrm{OR}=1.01,95 \% \mathrm{CI}$ [1.00 to 1.02$]$ ) were factors associated with higher odds of recent cessation attempts in the pooled analysis. The health warning on cigarette packets was a stronger motivation to stop smoking for current smokers who tried to stop smoking than for those who never tried to stop (50.3\% versus 38.9\%; $P=0.016)$.

\section{Media and advertising}

One of the most efficient methods to deliver information to the public about the hazards of smoking is through mass media with its different platforms reaching a wide population range. In a study by Wakefield et al. (55), which covered 17 low- and middle-income countries, investigators tested five types of advertisements and found that three advertisements with graphic demonstrations performed consistently high across all countries. Two advertisements showed diseased body parts and one used a disgust-provoking metaphor to demonstrate tar accumulation in smokers' lungs. A personal testimonial advertisement did more variably, as many smokers did not appreciate that the featured woman's lung cancer was attributable to smoking or that her changed physical appearance was due to chemotherapy.

An advertisement using a visual metaphor for pulmonary disease was also more erratic, mostly due to lack of understanding of the term 'emphysema'. Odds ratios (95\% CI) in Egypt were as follows: acceptance of message (1.29, 95\% CI [0.90 to 1.84]), personalized perceived effectiveness (1.91, 95\% CI [1.37 to 2.66]), uncomfortable (2.53, 95\% CI [1.93 to 3.31]), disgust (1.90, 95\% CI [1.45 to 2.50]). This confirms the findings by Durkin et al. (56) that the 'type of ad' is the most important variable. Significant interactions between the type of advertisement and gender or parental status were found on the acceptance of message (all $P$ values < 0.05), while an inclination towards a significant interaction was found for age $(P<0.10)$. In Egypt, non-health effects advertisements were rated by far the lowest in any country.

As for the media outlets, Caixeta et al. (57) analyzed the data, released by GATS, and found that in Egypt, 65.3\% of participants reported noticing anti-smoking information in the previous last 30 days in any of four media channels (television, radio, billboards, and newspapers or magazines), but mostly in TV (54.4\%).

Strong graphic advertisements showing the negative health effects of smoking may be the most suitable for quick adaptation and broad population broadcast in lowand middle-income countries, while advertisements that feature personal testimonials or those with complex medical terms or metaphors, are more variable and at least necessitate more careful pre-testing and adaptation to maximize their potential.

\section{Government laws and policies}

Government and health organizations should introduce new laws and bills for smoking cessation to improve public health. Public opinion strongly agrees with development of firmer legislation as found in a public health survey in Alexandria governorate by Youssef et al. (24). The majority of the interviewed subjects (98\%) expressed support of the government in executing a 100\% smoke-free indoor legislation in all public places and public transport. Another study found that nonsmokers preferred smoking restriction in public areas as the most suitable legislative action to fight smoking (93.2\%).

The Global Adult Tobacco Survey (GATS) is a nationwide representative household survey that collects data on adult tobacco use and key measures for tobacco control. It was conducted in 16 middle- and low-income countries where more than half of the world's smokers live, including Egypt. Multiple studies included in this review were secondary data analysis from the GATS results. To aid in the country-level implementation of effective interventions, WHO introduced the "MPOWER" actions (Monitoring tobacco use and prevention policies, Protecting people from tobacco smoke, Offering help to quit tobacco use, Warning about the dangers of tobacco, 
Enforcing bans on tobacco advertising, promotion and sponsorship, and Raising taxes on tobacco) to reduce the demand on tobacco in the countries applying the Framework Convention on Tobacco Control (FCTC) (2).

In 2011, Heydari et al. conducted a study to assess tobacco control strategies in 22 countries of the Eastern Mediterranean Region (EMR). Egypt scores were as follows: price of packet of cigarettes (17 out of 30), tobacco smoke-free public places (4.2 out of 22), national budget for tobacco control activities (9 out of 15), comprehensive ban on tobacco advertising and promotion (10 out of 13), health warning labels (8 out of 10), and treatment to help tobacco smokers stop (3 out of 10) (58).

Two years after adopting the MPOWER strategy in Egypt, Heydari et al. performed another study to assess the performance of tobacco control according to MPOWER policy. Their findings showed that after two years of implementing MPOWER policy in Egypt, tobacco control programmes are improving overall, although the desired results have yet to be achieved (59).

Although these efforts exist to control tobacco smoking, WHO predictions estimate that if these efforts continue at the same intensity, around $31 \%$ of the Egyptian population will be smokers by 2025, compared to $22 \%$ in 2010 . According to the data released by GATS and the Egyptian demographic and health survey, $43 \%$ of males and $1 \%$ of females are currently using tobacco. Considering WHO estimates, $63 \%$ of men and $0 \%$ of women will be smokers by $2025(2,60)$.

In 2013, the World Health Assembly established the noncommunicable diseases (NCD) tobacco target, which contains a plan to reduce the current prevalence of tobacco smoking among persons aged $>15$ years by $30 \%$ in 2025. The 2015 WHO estimates state that Egypt will not achieve this goal by 2025 if it adopts the global NCD tobacco target. Further efforts are needed such as preventing smoking in private offices or restaurants, bans on advertising and promotion, requirements for large graphic warnings on cigarette packs, and reasonably high taxes (59).

\section{Discussion}

Based on our review of the literature, we found that most published studies and established smoking prevention programmes in Egypt are directed towards adults, while data on adolescent smoking are less prevalent. Prevention of smoking initiation in adolescents is essential since once adolescents start to smoke, the effects of prevention programmes reduce dramatically (52).

Also, most data in the literature about tobacco smoking in Egypt are centered on cigarette smoking, although other methods of tobacco use are widely prevalent in the Egyptian community such as shisha (waterpipe) and narghile. Most of the smoking prevention programs in Egypt depend on mass media. However, there are no studies to estimate the prevalence of smoking in the general population on an annual basis to investigate if these programs are successful.
Religious beliefs are prevalent in the Egyptian population; however, their effect on tobacco use behaviours is not adequately investigated in the current literature. Several studies reported that the prevalence of smoking is unacceptably high in Muslim countries, while anti-smoking legislation is poorly enforced in those countries $(61,62)$. Several religious scholars in the Middle East have recently declared that tobacco smoking is prohibited (Haram); however, this declaration (Fatwa) needs to be conveyed to a wider population (63).

\section{Limitations}

The search strategy of this review was limited to studies in the English language. The data extracted from included studies were heterogenous in terms of measurement tools, timing of collection, and setting of study implementation; therefore, pooling them would provide inaccurate total estimates. Moreover, we did not perform subgrouping by the method of tobacco smoking such as cigarettes, shisha, narghile, and waterpipe. Most of the included studies in this scoping review were crosssectional or case-control studies. The main problems of these studies are possible bias and reverse causality. Cohort studies usually provide a more robust form of evidence to support temporal association between smoking and different medical diseases, but they are expensive. Most of the research in Egypt is self-funded, which might explain the popularity of cross-sectional studies.

\section{Recommendations}

Based on surveying the current literature about tobacco smoking status in Egypt, recommendations are suggested that should be addressed by health and law policy makers. These recommendations can be summarized in the following points:

1. Health care workers and family physicians, in particular, should be trained to deliver smoking cessation counseling, since the current literature indicates that the Egyptian health personnel are not well trained to offer such service to their patients (50).

2. Health education programmes should be standardized to reach a wide range of the Egyptian population and be delivered through mass media and schoolbased prevention programmes targeting high-risk adolescent groups (33). These programmes should also aim at educating Egyptian females, who are being targeted by tobacco companies under the false message of liberty and equality.

3. Governmental and health organizations should introduce new laws for smoking cessation and apply measures to enforce it (24).

4. Motivational interviewing and treatment of psychiatric disorders are essential elements of abstinence and relapse prevention (28).

5. Further annual studies are needed on the efficacy of smoking prevention programs and the objective of these studies should be extended to investigate 
the epidemiology of all types of smoking, especially narghile and waterpipe, since the current literature on these methods of tobacco smoking is deficient.

\section{Conclusion}

The prevalence of smoking in Egypt in 2010 is 22\% and is intensively increasing. Highest odds ratios were reported for sibling, parent, and peer smoking, as well as exposure to Western media as risk factors for smoking in Egypt. Cardiovascular complications, bladder and GIT cancers, COPD, erectile dysfunction, and fetal malformation are common health complications of smoking in Egypt. Efforts to control tobacco smoking are available, but inadequate. Proper training of healthcare workers to help their patients stop smoking is a must. Health education programmes should be standardized and delivered through mass media and school based programmes to reach a wide range of the Egyptian population.

Funding: None.

Competing interests: None declared. 


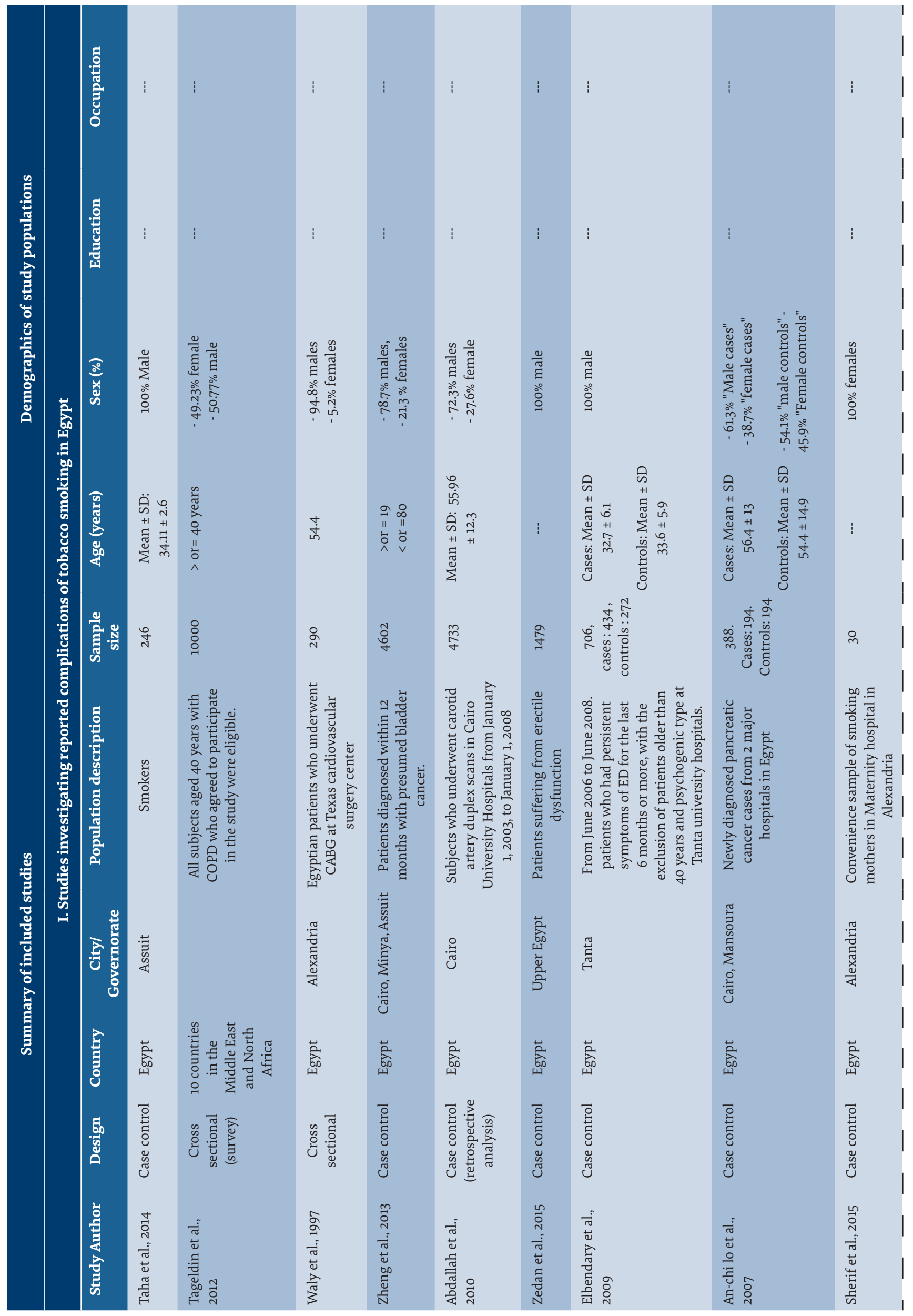




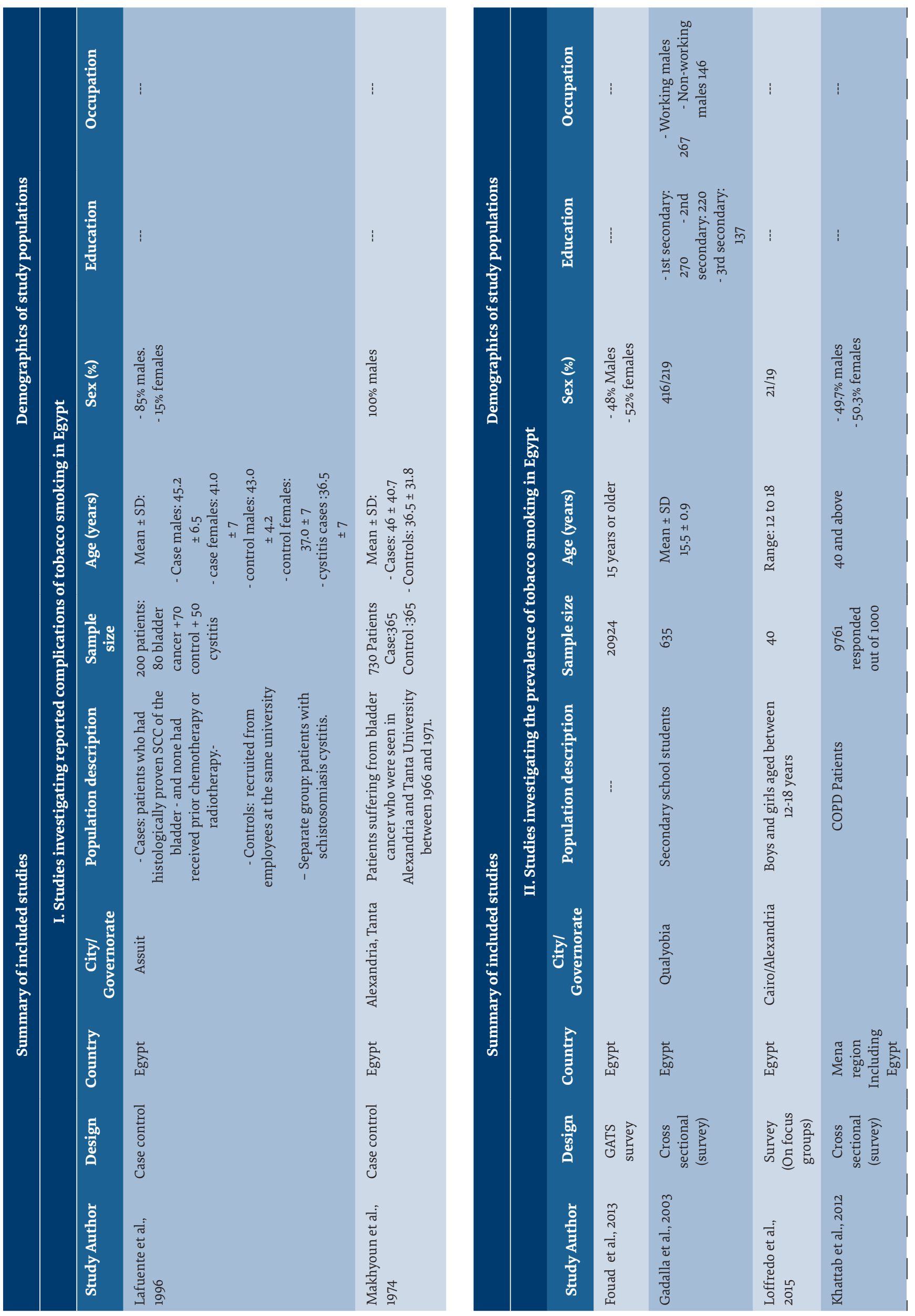




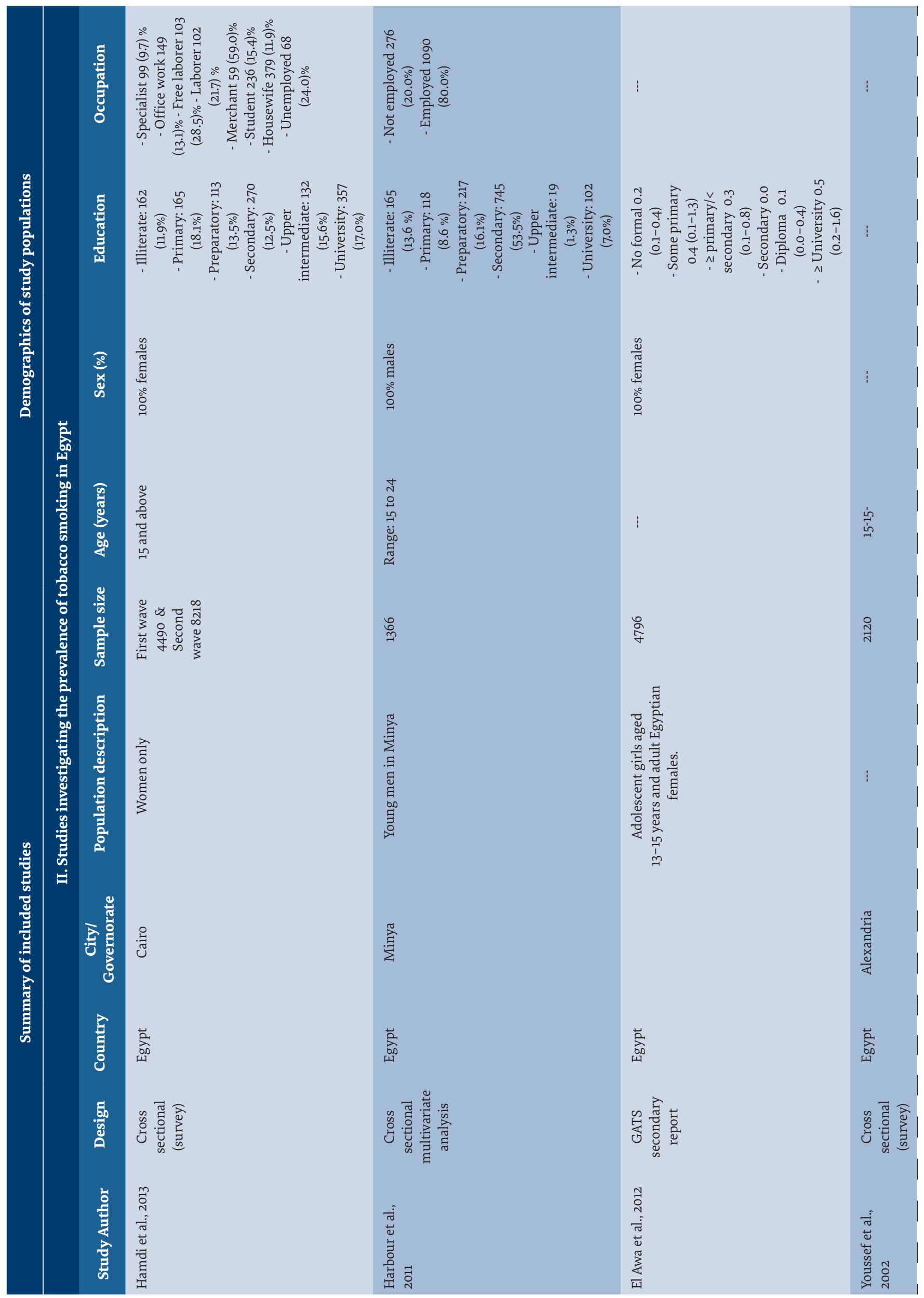




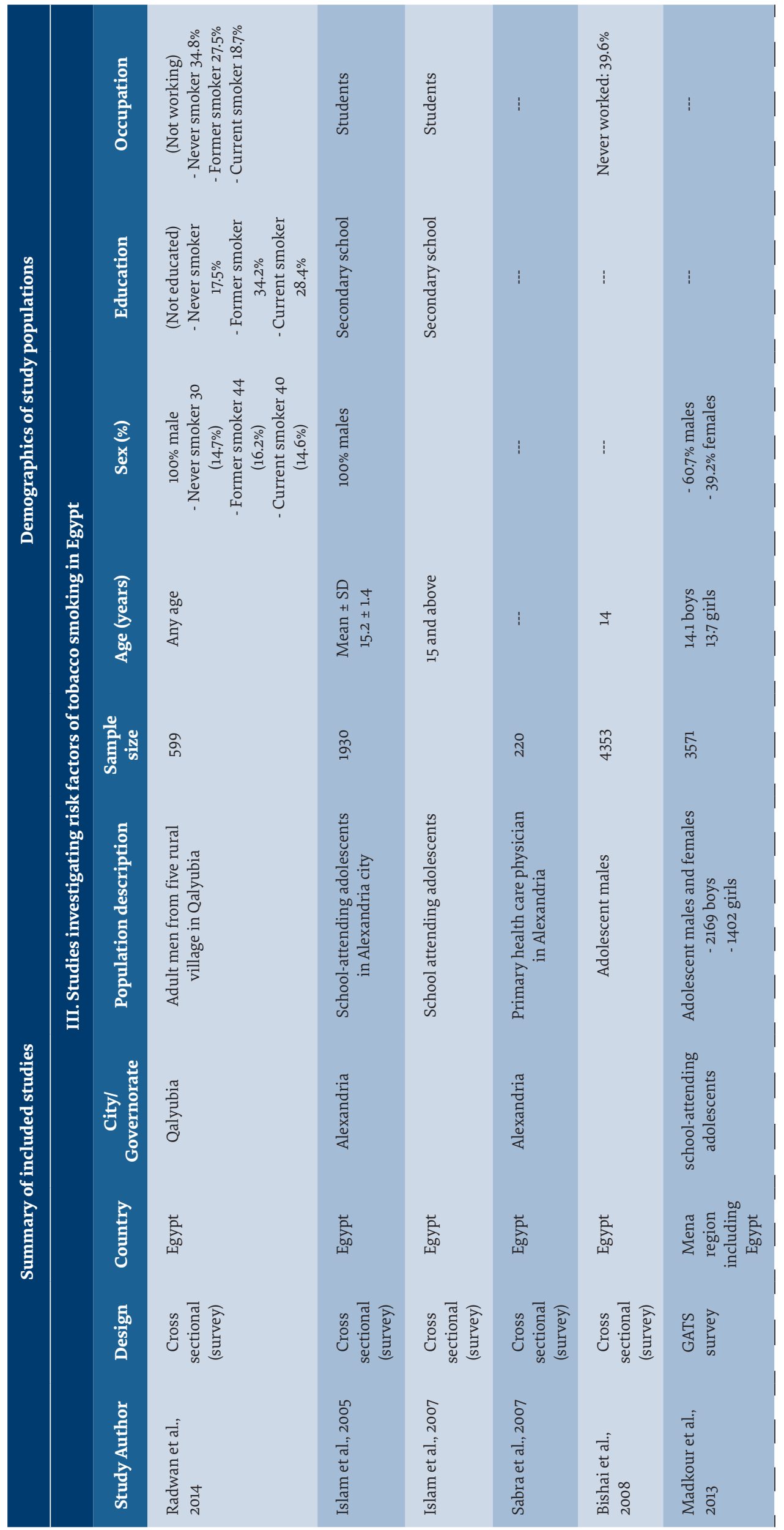




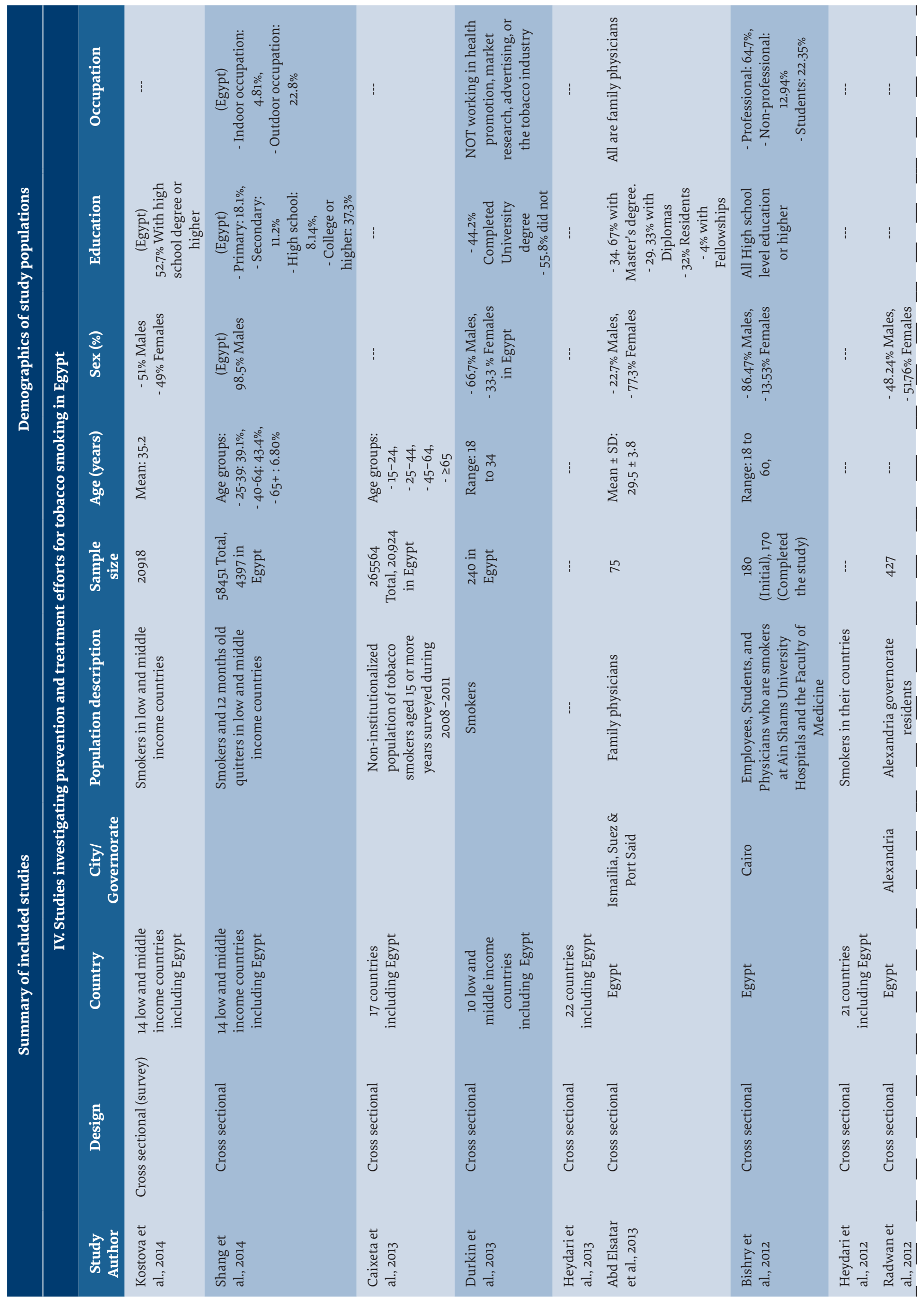




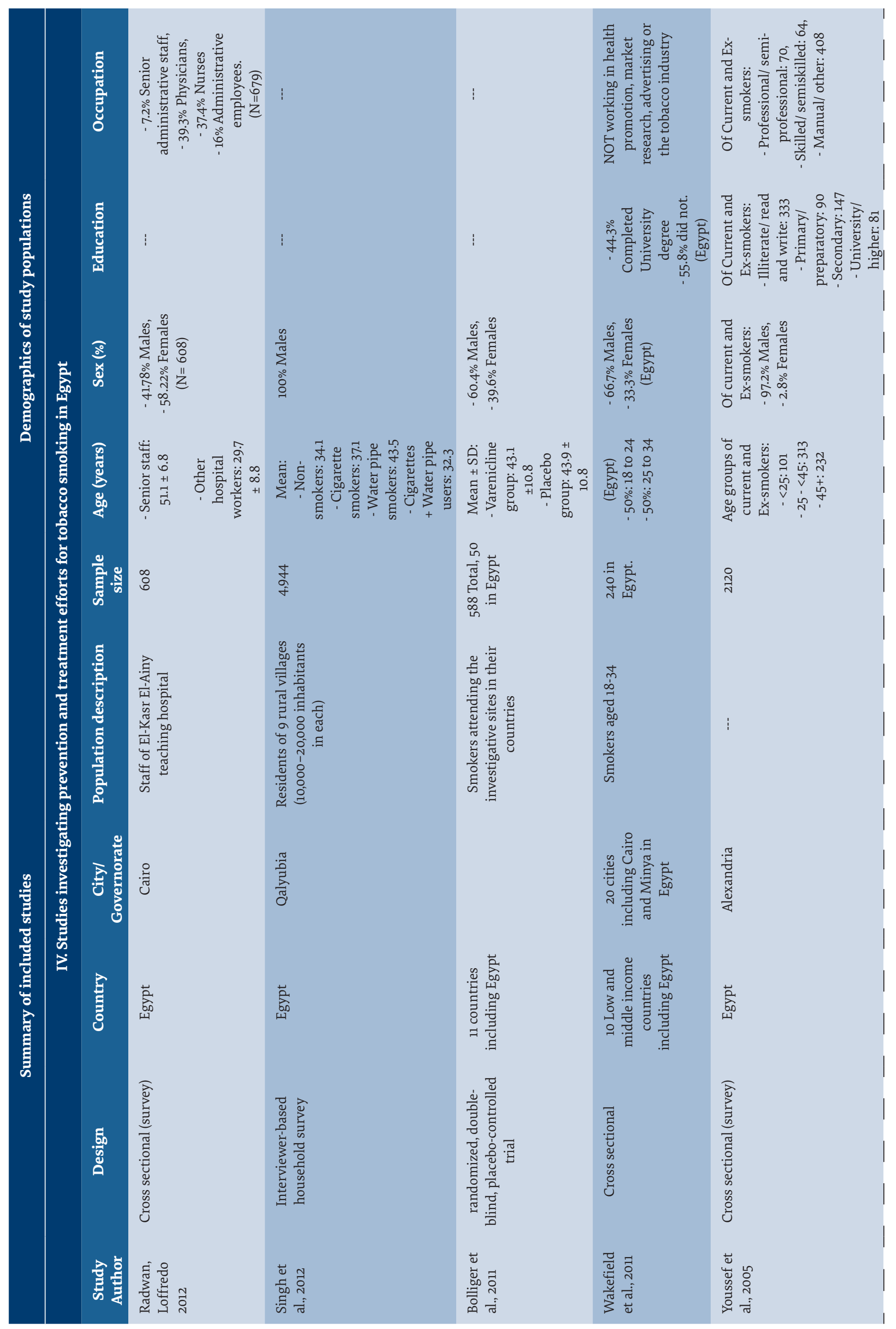




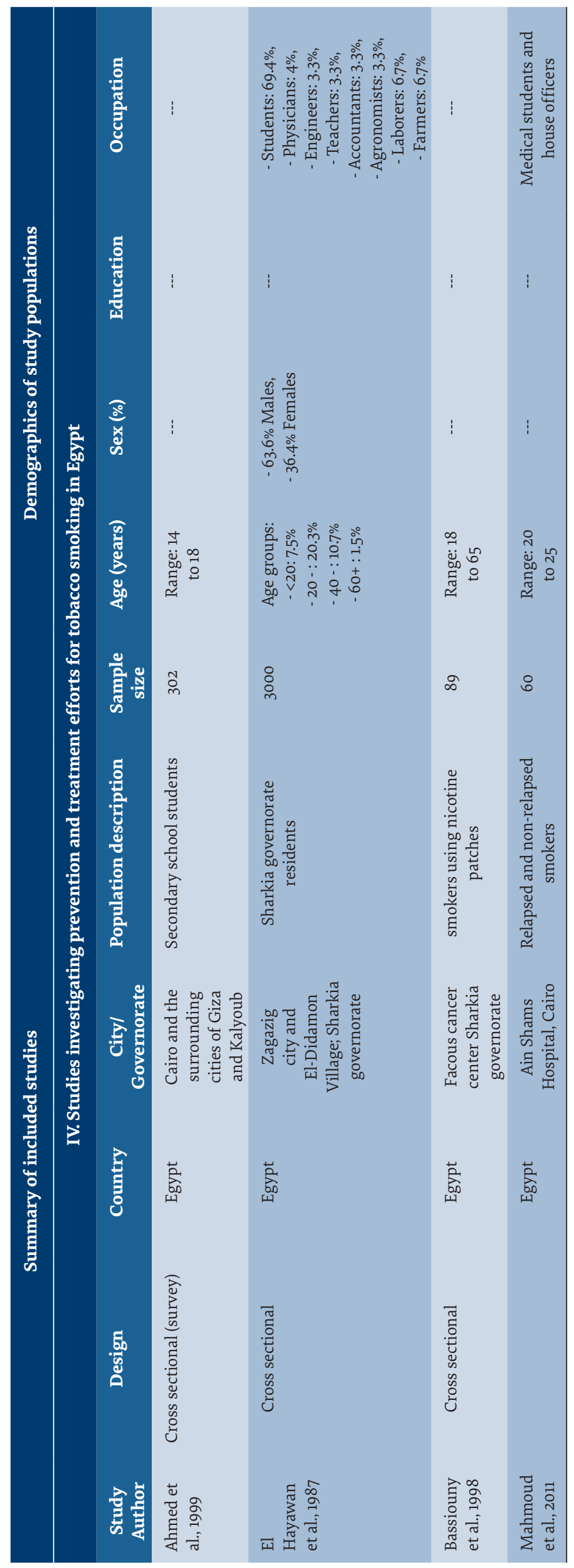




\section{Le tabagisme en Égypte : revue bibliographique exploratoire de son épidémiologie et des mesures de lutte}

\section{Résumé}

Contexte : Selon les rapports de l'OMS, la prévalence du tabagisme est en augmentation dans de nombreux pays en développement, dont l'Égypte. La présente étude avait pour objectif de synthétiser l'ensemble des données publiées dans la littérature sur le tabagisme en Égypte.

Méthodes: Une recherche documentaire sur ordinateur dans PubMed et d'autres revues égyptiennes pertinentes a été effectuée à l'aide de mots-clés. Les résultats des études extraites ont été compilés et discutés.

Résultats : Notre recherche a permis d'extraire 44 études pertinentes. Des odds ratios hautement significatifs ont été rapportés pour le fait d'avoir des frères et sœurs, des parents et des amis fumeurs en tant que facteurs de risque. Les troubles cardio-vasculaires, les tumeurs malignes, et les dysfonctionnements érectiles sont des complications courantes du tabagisme dans la population égyptienne. Des mesures pour lutter contre le tabagisme sont disponibles, mais ne sont pas adaptées.

Conclusions : Le tabagisme constitue un problème de santé prévalent en Égypte, associé aux troubles cardio-vasculaires et aux tumeurs malignes. Une éducation sanitaire devrait être dispensée à travers les médias de masse et dans le cadre de programmes menés dans les écoles afin d'atteindre une frange importante de la population égyptienne.

$$
\begin{aligned}
& \text { تدخين التبغ في مصر : استعر اض استطلاعي للدر اسات السابقة بشأن وبائيات التدخين وتدابير مكافحته } \\
& \text { سمر فودة، محمد كيلاني، ندى مصطفى، عبد الرحمن إبر اهيم أبوشوك، عمرو حسان، أحمد سليم، أسامة خختار، أحمد نجيدة، مدحت بسيوني } \\
& \text { الخلاصة }
\end{aligned}
$$

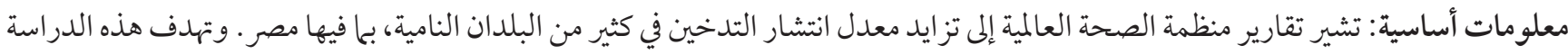

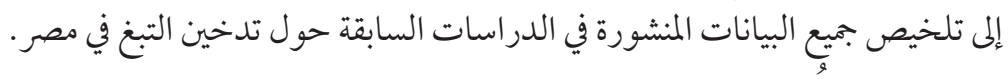

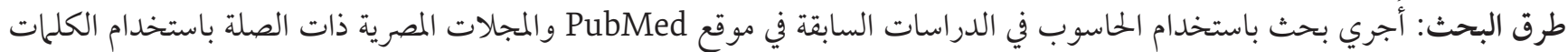

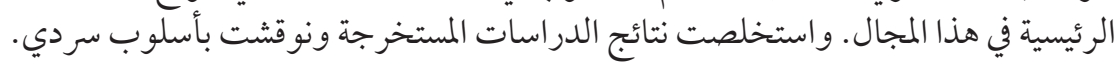

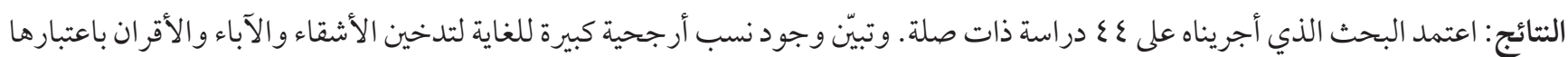

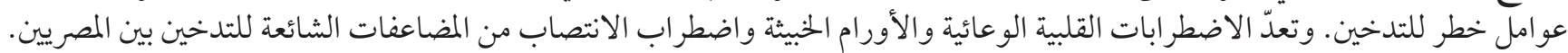

$$
\begin{aligned}
& \text { وثمة جهود حالية لمكافحة تدخين التبغ، لكنها لئنس اليست كافية. }
\end{aligned}
$$

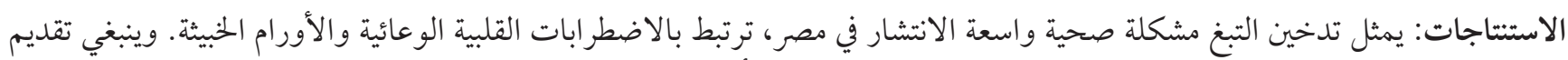

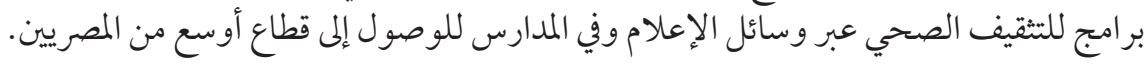

\section{References}

1. Jha P. Avoidable global cancer deaths and total deaths from smoking. Nat Rev Cancer. 2009 Sep;9(9):655-64. https://doi. org/10.1038/nrc2703

2. World Health Organization. WHO global report on trends in prevalence of tobacco smoking 2015. Geneva: World Health Organization; 2015

3. Hecht SS. Cigarette smoking: cancer risks, carcinogens, and mechanisms. Langenbecks Arch Surg. 2006 Nov;391(6):603-13. https://doi.org/10.1007/s00423-006-0111-z PMID:17031696

4. Adena MA, Gallagher HG. Cigarette smoking and the age at menopause. Ann Hum Biol. 1982 Mar-Apr;9(2):121-30. https://doi. org/10.1080/03014468200005591 PMID:7081945

5. Ockene IS, Miller NH; American Heart Association Task Force on Risk Reduction. Cigarette smoking, cardiovascular disease, and stroke: a statement for healthcare professionals from the American Heart Association. Circulation. 1997 Nov 4;96(9):3243-7. https://doi.org/10.1161/01.CIR.96.9.3243 PMID:9386200

6. Goldstein LB, Bushnell CD, Adams RJ, Appel LJ, Braun LT, Chaturvedi S, et al.; American Heart Association Stroke Council; Council on Cardiovascular Nursing; Council on Epidemiology and Prevention; Council for High Blood Pressure Research; Council on Peripheral Vascular Disease, and Interdisciplinary Council on Quality of Care and Outcomes Research. Guidelines for the primary prevention of stroke: a guideline for healthcare professionals from the American Heart Association/American Stroke Association. Stroke. 2011 Feb;42(2):517-84. https://doi.org/10.1161/STR.obo13e3181fcb238 PMID:21127304

7. Lin H-H, Ezzati M, Murray M. Tobacco smoke, indoor air pollution and tuberculosis: a systematic review and meta-analysis. PLoS Med. 2007 Jan;4(1):e20. https://doi.org/10.1371/journal.pmed.0040020 PMID:17227135 
8. Center for Disease Control. The Global Adult Tobacco Survey (GATS), Egypt-Fact Sheets. Atlanta, GA: Center for Disease Control; 2010.

9. March HN, March HN. The economics of tobacco in egypt. Polit Sci. 2003.

10. Nassar H. The economics of tobacco in Egypt: a new analysis of demand. Tob Control. 2003.

11. Assaad R, Roudi-Fahimi F. Youth in the Middle East and North Africa: Demographic opportunity or challenge. Washington DC: Population Reference Bureau Washington; 2007.

12. World Health Organization. The tobacco industry's tactics and plans to undermine control efforts in Egypt and North Africa. Geneva: World Health Organization; 2003.

13. Tobacco control laws in Egypt. (http://www.tobaccocontrollaws.org/legislation/country/Egypt/summary)

14. Daudt HML, van Mossel C, Scott SJ. Enhancing the scoping study methodology: a large, inter-professional team's experience with Arksey and O'Malley's framework. BMC Med Res Methodol. 201303 23;13(1):48. https://doi.org/10.1186/1471-2288-13-48 PMID:23522333

15. World Health Organization. Global Adult Tobacco Survey (GATS): Egypt Country Report 2009. Geneva: World Health Organization; 2010.

16. Khattab A, Javaid A, Iraqi G, Alzaabi A, Ben Kheder A, Koniski ML, et al.; BREATHE Study Group. Smoking habits in the Middle East and North Africa: results of the BREATHE study. Respir Med. 2012 Dec;106 Suppl 2:S16-24. https://doi.org/10.1016/So9546111(12)70011-2 PMID:23290700

17. Fouad H, El Awa F, El Naga RA, Emam AH, Labib S, Palipudi KM, et al. Prevalence of tobacco use among adults in Egypt, 2009. Glob Health Promot. 2013;0(0):1-10. PMID:24042971

18. Harbour C. Descriptive norms and male youth smoking in rural Minya, Egypt: a multilevel analysis of household and neighborhood normative influences. Nicotine Tob Res. 2012 Jul;14(7):840-8. https://doi.org/10.1093/ntr/ntr296 PMID:22271611

19. Palipudi KM, Gupta PC, Sinha DN, Andes LJ, Asma S, McAfee T; GATS Collaborative Group. Social determinants of health and tobacco use in thirteen low and middle income countries: evidence from Global Adult Tobacco Survey. PLoS One. 2012;7(3):e33466. https://doi.org/10.1371/journal.pone.0033466 PMID:22438937

20. El Awa F, Fouad H, El Naga RA, Emam AH, Labib S. Prevalence of tobacco use among adult and adolescent females in Egypt. East Mediterr Health J. 2013 Aug;19(8):749-54. https://doi.org/10.26719/2013.19.8.749 PMID:24975361

21. Tessier JF, Nejjari C, Bennani-Othmani M. Smoking in Mediterranean countries: Europe, North Africa and the Middle-East. Results from a co-operative study. Int J Tuberc Lung Dis. 1999 Oct;3(10):927-37. PMID:10524592

22. Nakkash RT, Khalil J, Afifi RA. The rise in narghile (shisha, hookah) waterpipe tobacco smoking: a qualitative study of perceptions of smokers and non smokers. BMC Public Health. 201105 14;11(1):315. https://doi.org/10.1186/1471-2458-11-315 PMID:21569577

23. Hamdi E, Sabry N, Khoweiled A, Edward A, Enaba D. The National Addiction Research Program : prevalence of alcohol and substance use among women in Cairo. Egypt J Psychiatry. 2013;34(3):155-63.

24. Youssef RM, Abou-Khatwa SA, Fouad HM. Prevalence of smoking and age of initiation in Alexandria, Egypt. East Mediterr Health J. 2002 Jul-Sep;8(4-5):626-37. PMID:15603046

25. Akl EA, Gunukula SK, Aleem S, Obeid R, Jaoude PA, Honeine R, et al. The prevalence of waterpipe tobacco smoking among the general and specific populations: a systematic review. BMC Public Health. 201104 19;11(1):244. https://doi.org/10.1186/1471-2458-11244 PMID:21504559

26. Gadalla S, Aboul-Fotouh A, El-Setouhy M, Mikhail N, Abdel-Aziz F, Mohamed MK, et al. Prevalence of smoking among rural secondary school students in Qualyobia governorate. J Egypt Soc Parasitol. 2003 Dec;33(3) Suppl:1031-50. PMID:15119469

27. Loffredo CA, Boulos DNK, Saleh DA, Jillson IA, Garas M, Loza N, et al. Substance use by Egyptian youth: current patterns and potential avenues for prevention. Subst Use Misuse. 2015 Apr;50(5):609-18. https://doi.org/10.3109/10826084.2014.997391 PMID:25629955।

28. Radwan GN, Loffredo CA, Abdelaziz H, Amr S. Associations of depression and neuroticism with smoking behavior and motives among men in rural Qalyubia (Egypt). J Egypt Public Health Assoc. 2014 Apr;89(1):16-21. https://doi.org/10.1097/01. EPX.0000444060.91661.6f PMID:24717396

29. Madkour AS, Ledford EC, Andersen L, Johnson CC. Tobacco advertising/promotions and adolescents' smoking risk in Northern Africa. Tob Control. 2014 May;23(3):244-52. https://doi.org/10.1136/tobaccocontrol-2012-050593 PMID:23303288

30. Sitrin D, Bishai D. The association between cigarette smoking and work status among Egyptian adolescent males. The international journal of tuberculosis and lung disease : the official journal of the International Union against Tuberculosis and Lung Disease. 2008 Jun;12(6):670-6

31. Sabra AA. Smoking attitudes, behaviours and risk perceptions among primary health care personnel in urban family medicine centers in Alexandria. J Egypt Public Health Assoc. 2007;82(1-2):43-64. PMID:18217324

32. Islam SM, Johnson CA. Western media's influence on Egyptian adolescents' smoking behavior: the mediating role of positive beliefs about smoking. Nicotine Tob Res. 2007 Jan;9(1):57-64. https://doi.org/10.1080/14622200601078343 PMID:17365737

33. Islam SMS, Johnson CA. Influence of known psychosocial smoking risk factors on Egyptian adolescents' cigarette smoking 
behavior. Health Promot Int. 2005 Jun;20(2):135-45. https://doi.org/10.1093/heapro/dah604 PMID:15722365

34. Abd Allah F, Baligh E, Ibrahim M. Clinical relevance of carotid atherosclerosis among Egyptians: a 5-year retrospective analysis of 4,733 subjects. Neuroepidemiology. 2010;35(4):275-9. https://doi.org/10.1159/000319899 PMID:20881431

35. Tageldin MA, Nafti S, Khan JA, Nejjari C, Beji M, Mahboub B, et al.; BREATHE Study Group. Distribution of COPD-related symptoms in the Middle East and North Africa: results of the BREATHE study. Respir Med. 2012 Dec;106 Suppl 2:S25-32. https:// doi.org/10.1016/S0954-6111(12)70012-4 PMID:23290701

36. Lafuente A, Zakahary MM, el-Aziz MA, Ascaso C, Lafuente MJ, Trias M, et al. Influence of smoking in the glutathione-Stransferase $\mathrm{M} 1$ deficiency-associated risk for squamous cell carcinoma of the bladder in schistosomiasis patients in Egypt. Br J Cancer. 1996 Sep;74(5):836-8. https://doi.org/10.1038/bjc.1996.445 PMID:8795591

37. Makhyoun NA. Smoking and bladder cancer in Egypt. Br J Cancer. 1974 Dec;30(6):577-81. https://doi.org/10.1038/bjc.1974.238 PMID:4447786

38. Zheng Y-L, Amr S, Saleh D a., Dash C, Ezzat S, Mikhail NN, et al. Urinary bladder cancer risk factors in egypt: a multi-center casecontrol study. 2013;21(202):537-46.

39. Lo A-C, Soliman AS, El-Ghawalby N, Abdel-Wahab M, Fathy O, Khaled HM, et al. Lifestyle, occupational, and reproductive factors in relation to pancreatic cancer risk. Pancreas. 2007 Aug;35(2):120-9. https://doi.org/10.1097/mpa.obo13e318053e7d3 PMID:17632317

40. Elbendary MA, El-Gamal OM, Salem KA. Analysis of risk factors for organic erectile dysfunction in Egyptian patients under the age of 40 years. J Androl. 2009 Sep-Oct;30(5):520-4. https://doi.org/10.2164/jandrol.108.007195 PMID:19234310

41. Zedan H, Hareadei AA, Abd-Elsayed AA, Abdel-Maguid EM. Cigarette smoking, hypertension and diabetes mellitus as risk factors for erectile dysfunction in upper Egypt. East Mediterr Health J. 2010 Mar;16(3):281-5. PMID:20795441

42. Taha E a., Ezz-Aldin a. M, Sayed SK, Ghandour NM, Mostafa T. Smoking influence on sperm vitality, DNA fragmentation, reactive oxygen species and zinc in oligoasthenoteratozoospermic men with varicocele. Andrologia. 2014;46(Vx):687-91.

43. Bardy AH, Seppälä T, Lillsunde P, Kataja JM, Koskela P, Pikkarainen J, et al. Objectively measured tobacco exposure during pregnancy: neonatal effects and relation to maternal smoking. Br J Obstet Gynaecol. 1993 Aug;100(8):721-6. https://doi. org/10.1111/j.1471-0528.1993.tb14262.x PMID:8399009

44. Na S, Sm K, Os AA, Oa S, Ea S, Ea H. Detection of cotinine in neonate meconium as a marker for nicotine exposure in utero . who. int. 2015;10:16201714.

45. Bassiouny, MR, Abdel Latif A, Abdel Ralzmaii H, El Ainin E, Abdel Azeein I, Abdel Aal. Predictors of Relapse in Smoking Cessation with Nicotine Patches. Egyptian Journal of Psychiatry. 1998;(2).

46. El-hayawan HM, Refaat A, Refaat AGA, Mobasher AMT. Smoking cessation profile in Sharkia governorate. Zagazig Univ Med J. 1998;4(2)

47. Youssef RM, Abou Khatwa SA, Fouad HM. Tobacco cessation in a population over age 15 years: a community-based survey in Alexandria. East Mediterr Health J. 2005 May;11(3):287-99. PMID:16602447

48. Bishry Z, Fekry M, El Shahawy H, Soltan M, Haroun A, Moneim DA. The role of personality profile in the motivation to quit smoking. Middle East Current Psychiatry. 2012;19(4):206-13. https://doi.org/10.1097/01.XME.0000418790.39675.f9

49. Radwan GN, Loffredo CA, Aziz R, Abdel-Aziz N, Labib N. Implementation, barriers and challenges of smoke-free policies in hospitals in Egypt. BMC Res Notes. 201210 15;5(1):568. https://doi.org/10.1186/1756-0500-5-568 PMID:23069011

50. Eldein HN, Mansour NM, Mohamed SF. Knowledge, attitude and practice of family physicians regarding smoking cessation counseling in family practice centers, suez canal university, egypt. J Family Med Prim Care. 2013 Apr;2(2):159-63. https://doi. org/10.4103/2249-4863.117411 PMID:24479071

51. Abdel D, Mahmoud M, Bishry Z, Hamid A, Haroun A, Hamid EA, et al. State - trait anxiety and smoking abstinence. 2012;10-3.

52. Garrison MM, Christakis DA, Ebel BE, Wiehe SE, Rivara FP. Smoking cessation interventions for adolescents: a systematic review. Am J Prev Med. 2003 Nov;25(4):363-7. https://doi.org/10.1016/So749-3797(03)00213-7 PMID:14580641

53. Ahmed O Jr, Choi WS. Tobacco education in Cairo, adolescent smoking. Tob Control. 1999;1999(C):278-83. PMID:10712055

54. Shang C, Chaloupka F, Kostova D. Who quits? An overview of quitters in low- and middle-income countries. Nicotine Tob Res. 2014 Jan;16 Suppl 1:S44-55. https://doi.org/10.1093/ntr/ntt179 PMID:24343957

55. Wakefield M, Bayly M, Durkin S, Cotter T, Mullin S, Warne C; International Anti-Tobacco Advertisement Rating Study Team Smokers' responses to television advertisements about the serious harms of tobacco use: pre-testing results from 10 low- to middle-income countries. Tob Control. 2013 Jan;22(1):24-31. https://doi.org/10.1136/tobaccocontrol-2011-050171 PMID:21994276

56. Durkin S, Bayly M, Cotter T, Mullin S, Wakefield M. Potential effectiveness of anti-smoking advertisement types in ten low and middle income countries: do demographics, smoking characteristics and cultural differences matter? Soc Sci Med. 2013 Dec;98:204-13. https://doi.org/10.1016/j.socscimed.2013.09.022 PMID:24331900

57. Caixeta RB, Sinha DN, Khoury RN, Rarick J, Fouad H; Centers for Disease Control and Prevention (CDC). Antismoking messages and intention to quit - 17 countries, 2008-2011. MMWR Morb Mortal Wkly Rep. 2013 May 31;62(21):417-22. PMID:23718949

58. Heydari G, Talischi F, Algouhmani H, Lando HA, Ahmady AE. Tobacco control in the Eastern mediterranean according to MPOWER 2011. East Mediterr Health J. 2011;19(4) 
59. Heydari G, Talischi F, Algouhmani H, Lando HA, Ahmady AE. WHO MPOWER tobacco control scores in the Eastern Mediterranean countries based on the 2011 report. East Mediterr Health J. 2013 Apr;19(4):314-9. https://doi. org/10.26719/2013.19.4.314 PMID:23882955

6o. Organization WH. WHO report on the global tobacco epidemic, 2009: implementing smoke-free environments. 2009. Geneva: World Health Organization; 2009. pp. 8-11.

61. Kawachi I. More evidence on the risks of passive smoking. BMJ. 2005 Feb 5;330(7486):265-6. https://doi.org/10.1136/ bmj.330.7486.265 PMID:15695250

62. Bush J, White M, Kai J, Rankin J, Bhopal R. Understanding influences on smoking in Bangladeshi and Pakistani adults: community based, qualitative study. BMJ. 2003 May 3;326(7396):962. https://doi.org/10.1136/bmj.326.7396.962 PMID:12727770

63. Ghouri N, Atcha M, Sheikh A. Influence of Islam on smoking among Muslims. BMJ. 2006 Feb 4;332(7536):291-4. https://doi. org/10.1136/bmj.332.7536.291 PMID:16455732 